\title{
Lipomas of the Digestive Tract: General Aspects and Imaging
}

\author{
Lova Hasina Narindra Rajaonarison Ny Ony ${ }^{1}$, Ahmad Ahmad ${ }^{2}$, Jean Noel Bruneton ${ }^{2}$ \\ 1. CHU Bordeaux 2. Radiology, HJRA Ampefiloha Antananarivo, Madagascar
}

$\square$ Corresponding author: Lova Hasina Narindra Rajaonarison Ny Ony , rlovahasina@gmail.com Disclosures can be found in Additional Information at the end of the article

\section{Abstract}

Lipomas are the second most common benign, non-epithelial tumor of the gastrointestinal tract after leiomyoma. They can grow at all levels of digestive tract with a variable frequency. This involvement may be single or multiple in one or more segments. These lesions with a low development can rarely cause serious complications requiring prompt treatment. Therapeutic decision is guided by symptoms and tumor size. Conventional radiography with digestive opacification allows locating the tumor. On cross-sectional imaging, lipomas appear as homogeneous fatty tumors or rarely with internal fine septa. Computed tomography and magnetic resonance imaging allow the final diagnosis of lipomas in its uncomplicated forms.

Categories: Pathology, Radiology, Gastroenterology

Keywords: lipomas, digestive tract, imaging

\section{Introduction And Background}

Although rare, lipomas are the second most benign, non-epithelial tumor of the gastrointestinal tract after leiomyomas [1]. Most gastrointestinal tract lipomas are asymptomatic and will be discovered incidentally; they may, however, cause a wide spectrum of non-specific symptoms or mimic malignancy [2]. They can be seen at any age, with a discovery peak in the seventh decade and a discreet female predominance [3]. Before the advent of crosssectional imaging, the diagnosis was often difficult, because if the study with digestive opacification allowed prejudging the benign nature of the tumor, it did not allow specifying its etiology [4]. Currently, computed tomography (CT) and magnetic resonance imaging (MRI) allow the positive diagnosis by showing the pathognomonic greasy density or fat signal of these tumors [5-6]. We have done a review of the literature on the general appearance, the location, the clinical, and radiological aspects as well as the therapeutic management of these tumors.

Received 03/02/2014 Review began 03/02/2014 Review ended 09/14/2014 Published 09/19/2014

\section{C) Copyright 2014}

Narindra Rajaonarison Ny Ony et al. This is an open access article distributed under the terms of the Creative Commons Attribution License CC-BY 3.0., which permits unrestricted use, distribution, and reproduction in any medium, provided the original author and source are credited.

\section{Review}

\section{Anatomical general aspects}

Lipomas appear as a yellowish mass, rounded or oval, with regular or lobulated contour. At the level of the digestive tract, they can be sessile or pedunculated; these are tumors of slow growth that can affect the digestive tract at all levels [3-6]. The majority of these masses are from the submucosa (90\% to $95 \%$ ) and $5 \%$ to $10 \%$ are only subserosal [7-8]. Because of this very superficial position, and thanks to the strength of peristalsis, lipomas are easily attracted into the digestive lumen during their growth and form a polyp or an intraluminal pseudo-pedicle [4]. Often unique, lipomas of the gastrointestinal tract can be multiple [9-12] or can be exceptionally associated with other digestive tumor formations as stromal tumors and adenomatous polyps [13]. Franc Law evaluates the frequency of these multifocal 
gastrointestinal lipomas among $14 \%$ to $26 \%$ of the cases [14]. Anatomically, lipomas are to be differentiated from lipomatosis thanks to the presence of a collagen capsule, which allows a surgical enucleation. The presence of a superficial ulceration is common, but its mechanism is unclear and might involve a poor vascularization of this tumor [15]. Theunis [16] believes that it is the increase in volume of a lipoma that causes a responsible pressure to a mucosal ischemia; the corrosive action of the gastric juice could be then incriminated. However, Bruneton [4] noted the absence of a link between the size of the lipoma and the frequency of this ulceration.

Lipoma is composed of lobules of mature fat cells, similar to normal mature adipose tissue; it is poorly vascularized. Other cytological forms according to the composition of the tumor were rarely described: fibrolipoma, lipofibromyxoma, lipomyxoma, and angiolipoma [17]. A cystic transformation is possible [18]. No specific post-therapeutic follow-up is useful since lipomas have no malignant predisposition [19]. If the possibility of malignant transformation was considered in 1955 [1], a single case of liposarcomatous degeneration was reported in Korea by Bak YT in 1989 [20]. The reported sarcomatous degenerations touch cutaneous, retroperitoneal [21-23], or osseous [24] lipomas only. Incidentally, discovered extradigestive pathological associations, such as cutaneous lipomatosis, peripheral neuropathy, and hyperlipidemia, have been reported. The association with a multiple familial lipomatosis is poorly described [25]. The progressive apparition of lipomas within deep organs (colon) in patients with familial multiple lipomatosis has been reported [26].

\section{Lipomas of the esophagus}

General Characteristics

Lipoma of the esophagus is relatively rare. This entity, not exceeding $1.5 \%$ of all gastrointestinal lipomas, represents $15 \%$ of all benign tumors of the esophagus. It affects both genders but with a strong male predominance. This affection is generally diagnosed in adults after age 50, but severe pediatric cases have often been reported [27-28]. The preferred site is the upper third of the esophagus, but any other part can be affected [9]. Lipomas of the esophagus are very variable in size: the pedunculated forms are often the most voluminous ones, which can go up to more than $20 \mathrm{~cm}$ of height [29]. No multiple form of esophageal lipoma has been reported so far. Clinical symptomatology is highly variable. Esophageal lipomas remain asymptomatic for a long time and can reach a considerable size before causing clinical symptoms, often of an obstruction type [30]. Dysphagia is the most common symptom. A massive hemorrhage may occur by voluminous lipoma ulceration. Other minor signs, such as the sensation of fullness in the throat, dysphonia, sleep apnea, and many nonspecific symptoms (cough, weight loss, or asthenia), can be seen. The pedunculated lipoma can involve the vital risk by asphyxia through its possible regurgitation [31]. Indeed, this pedunculated tumor is potentially mobile, especially when it is located at the aerodigestive bifurcation or at the hypopharynx [3]. The endoscopy does not always allow the diagnosis because these tumors are often covered with normal mucosa. Patients with significant clinical symptoms or those who have an hemorrhagic complication require surgical management. Fumagalli has reported that all pedunculated lipomas of the esophagus present a surgery indication because they often may become symptomatic in a very severe way [29]. Given the frequency of these tumors of the upper third of the esophagus, a cervicotomy with resection of the mass is often the preferred technique. Small tumors are easily treated endoscopically with an excellent prognosis [32]. Currently, giant pedunculated tumors can be resected without difficulty by trans-oral route in diverticuloscope [29].

Imaging

The esophageal transit usually shows a pedunculated mass, often with regular contours, with 
possible dilatation of the esophagus upstream [33]. In this case, lipoma can be mistaken as an achalasia with overlying retention [34]. After a digestive opacification, this mass may present undulations related to an intrinsic peristalsis. It is often difficult to distinguish giant lipomas from sarcomas, especially when the surface is irregular or ulcerated. Also, the appearance may be identical to that of a polyp or leiomyoma. CT scan is the first-line examination to give a definitive diagnosis of lipoma when bringing out an homogeneous mass of greasy density between - 80 and $-120 \mathrm{HU}$ [35]. However, Taylor reported two cases in 1990 of heterogeneous lipomas with visible septas on CT and which corresponded to fibrovascular septas in histological study [3]. MRI brings out a mass of adipose component with high-intensity signal on $\mathrm{T} 1$ and intermediate to intense on $\mathrm{T} 2$; and it especially allows specifying the exact size and location of the mass and the pedicle so as to lead a prospective therapeutic procedure [29].

\title{
Lipomas of the stomach
}

\author{
General Characteristics
}

The stomach is the third site location of digestive tract lipomas with a percentage of $11.6 \%$ of all gastrointestinal lipomas [1]. Gastric lipomas constitute only $3 \%$ to $5 \%$ of all benign tumors of the stomach [36] and are less common than adenoma, leiomyoma, or stromal tumor [15]. The average age of patients at this diagnosis is 60 years, and both genders can be affected in the same way. These tumors are preferentially localized in the antrum, they are often solitary, with a size larger than $5 \mathrm{~cm}$ [4], and can then prolapse into the pylorus because of obstructive complications [3, 30]. Multifocal gastric lipomas are exceptional [9, 18]. These tumors are asymptomatic for a long time and so of a fortuitous discovery. The clinical manifestations of gastric lipomas are dependent upon their size and location. Ulceration and hemorrhage are frequent when the tumor size goes beyond $2 \mathrm{~cm}$ [37]. These are then signs of complication of hemorrhage [7, 38-39] or intussusceptions type, which lead to the diagnosis of these lesions. In endoscopy, like all other digestive lipomas, gastric lipomas appear to be covered with normal mucosal tissue, but they may also present as superficial ulcerations [36]. Therapeutically, surgery seems to be indicated for symptomatic patients only. It is a simple enucleation or resection or an antrectomy or partial gastrectomy for giant tumors [38]. The prognosis is excellent. No recurrence after excision or degeneration has been reported, which allows as much as possible a limited surgery.

Imaging

There is no specific sign of lipoma in eso-gastro-duodenal transit, but some signs may suggest the diagnosis: mass projecting on the gastric region over the unprepared layout, more or less regular mark on the layout with barium repletion, visible contours between the lipomatous formation, and the peritumoral sclerotic connective tissue. Intramural sessile tumors are smooth and appear as a rounded lacuna with regular contours. Frequent superficial ulcerations may imply a malignancy [7]. A lipoma causing intussusceptions is visible in the bulb, which is distended. The complete central invagination of the lower part of the stomach into the duodenum causes the opacification of the upper portion of the stomach associated with a huge antral lacunar image. In the case of a complete lateral invagination, the antral region is laminated and the upper portion of the bulb is amputated because of repression by the tumor [4]. The gastro-duodenal transit is negative in case of subserosal lipoma. In total, the radiological diagnosis is often that of a benign tumor (polyp or conjunctiva benign tumor). When it was performed, angiography showed a hypovascular mass associated with an attraction of peritumoral vessels but without the characteristics of malignancy [7]. The diagnosis is easily performed on CT or MRI for uncomplicated forms, highlighting the fat density or homogeneous fat signal, rarely heterogeneous with fine intralesional septa [3, 37] (Figure 1). The presence of ulceration or complication, such as intussusception, can make the diagnosis more difficult because the lesion becomes very heterogeneous $[35,37]$. 


\section{Cureus}

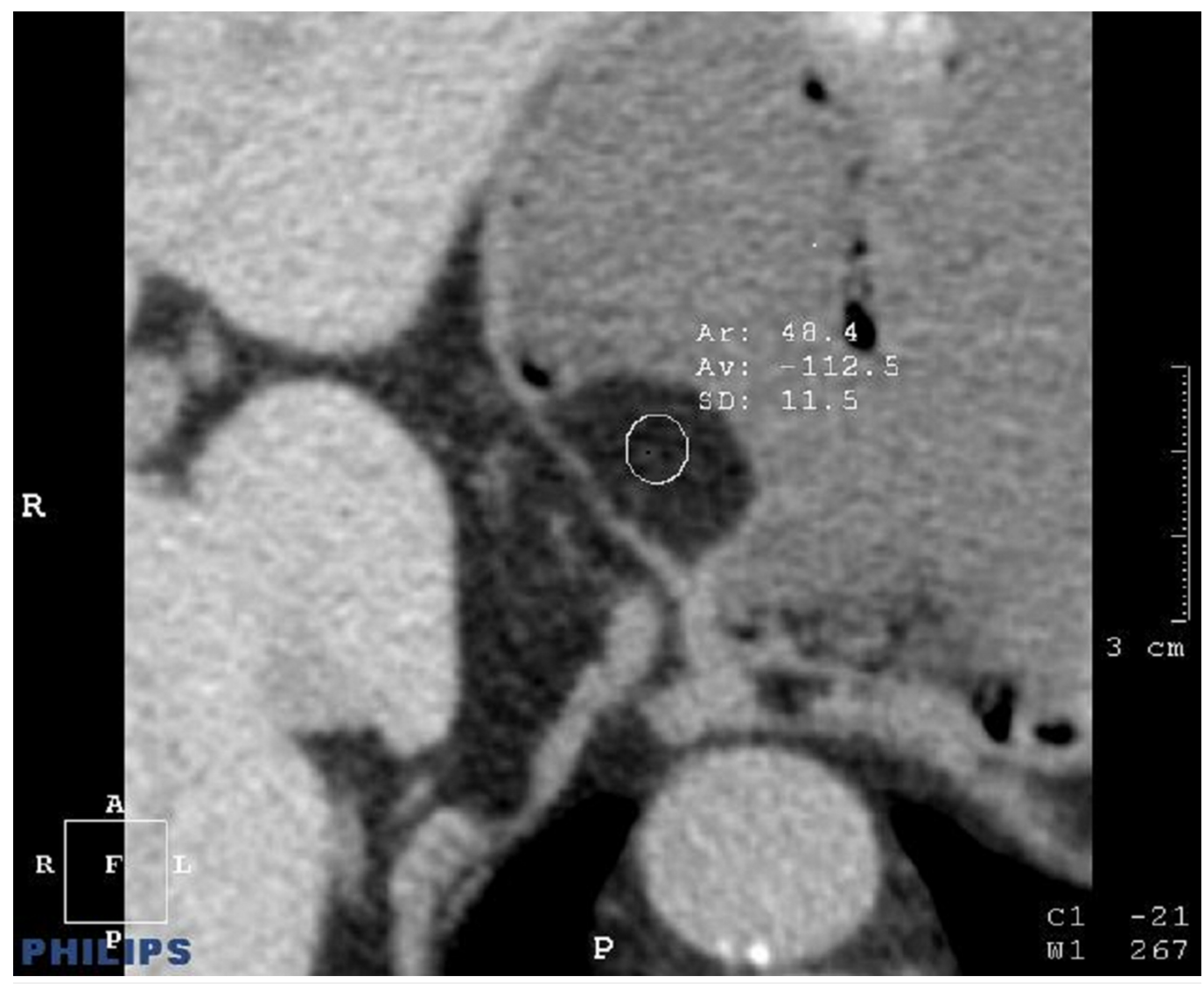

FIGURE 1: Axial computed tomography image

Hypodense mass of the stomach developed in the submucosa, related to a non-complicated gastric lipoma.

\section{Lipomas of the small intestine}

\section{General Characteristics}

Lipomas of the small intestine are the second gastrointestinal benign tumor at this level after stromal tumors [3]. They represent $13 \%$ to $15 \%$ of all the intestinal benign tumors [1] and less than $36 \%$ of all digestive tract lipomas [3-4, 7]. They are seen more frequently on ileal than on jejunal or on duodenal portion $[4,7,30]$. Lipomas of the small bowel are often solitary, but can be multifocal, and in this case, an association with Crohn's disease is possible [30]. Multifocal lipomas can be uni-segmental or pluri-segmental [9-10]. Lipomas of Meckel's diverticulum are rarely reported [1]. There is no affection predominance regarding gender, and the average age of diagnosis is 60 years. The average tumor size is $4 \mathrm{~cm}$ but it can reach to more than $30 \mathrm{~cm}$. These tumors have a clinical latency in the $43 \%$ of the cases reviewed by Bruneton, et al. [40]. Lipomas of the terminal ileum or the region of ileocecal valve can cause symptoms mimicking acute appendicitis [1]. A palpable mass often corresponds to an invagination rather than the tumor itself. Intussusception and hemorrhage constitute the major complications of these tumors [41-42]. Duodenal pedunculated lipomas can be treated endoscopically [42]. Other tumors require an enterotomy with complete resection. New endoscopic techniques have been developed recently to better manage the giant pedunculated lipomas [43].

Imaging

The barium transit shows a sessile or pedunculated tumor (Figure 2) whose shape is changing 


\section{Cureus}

on successive layouts in response to intestinal peristaltic activity. The translucent aspect of lipomas is rarely reported. When it was performed, the arteriography could show the lesion, without specifying its nature. In uncomplicated forms, CT shows a mass of pathognomonic homogeneous fat density [35] (Figure 3) or with intratumoral septa [3, 37]. In case of intussusception, CT diagnosis can become difficult if the tumor takes a complex aspect of mixed density [30]. The echography rarely shows an echogenic mass but can easily highlight the characteristic aspect in "pseudo- kidney" in case of intussusceptions [30]. On MRI, lipomas are hyperintense in T1 and of intermediate intensity to hyperintense in T2.

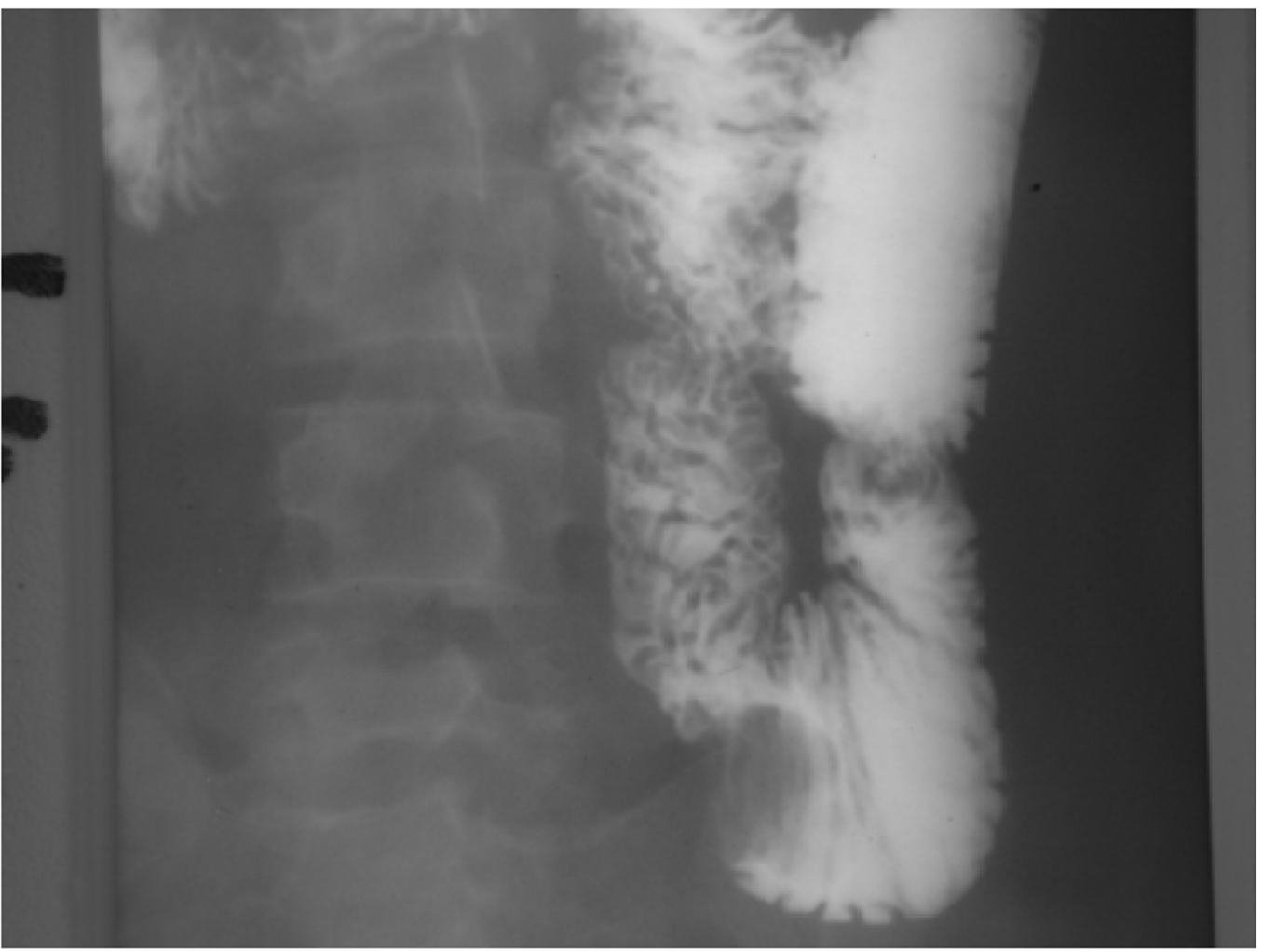

FIGURE 2: Plain radiograph of the abdomen after barium opacification of the digestive tract

Endoluminal lacuna with regular contours in ileal segment of the small bowel evoking a benign tumor. 


\section{Cureus}

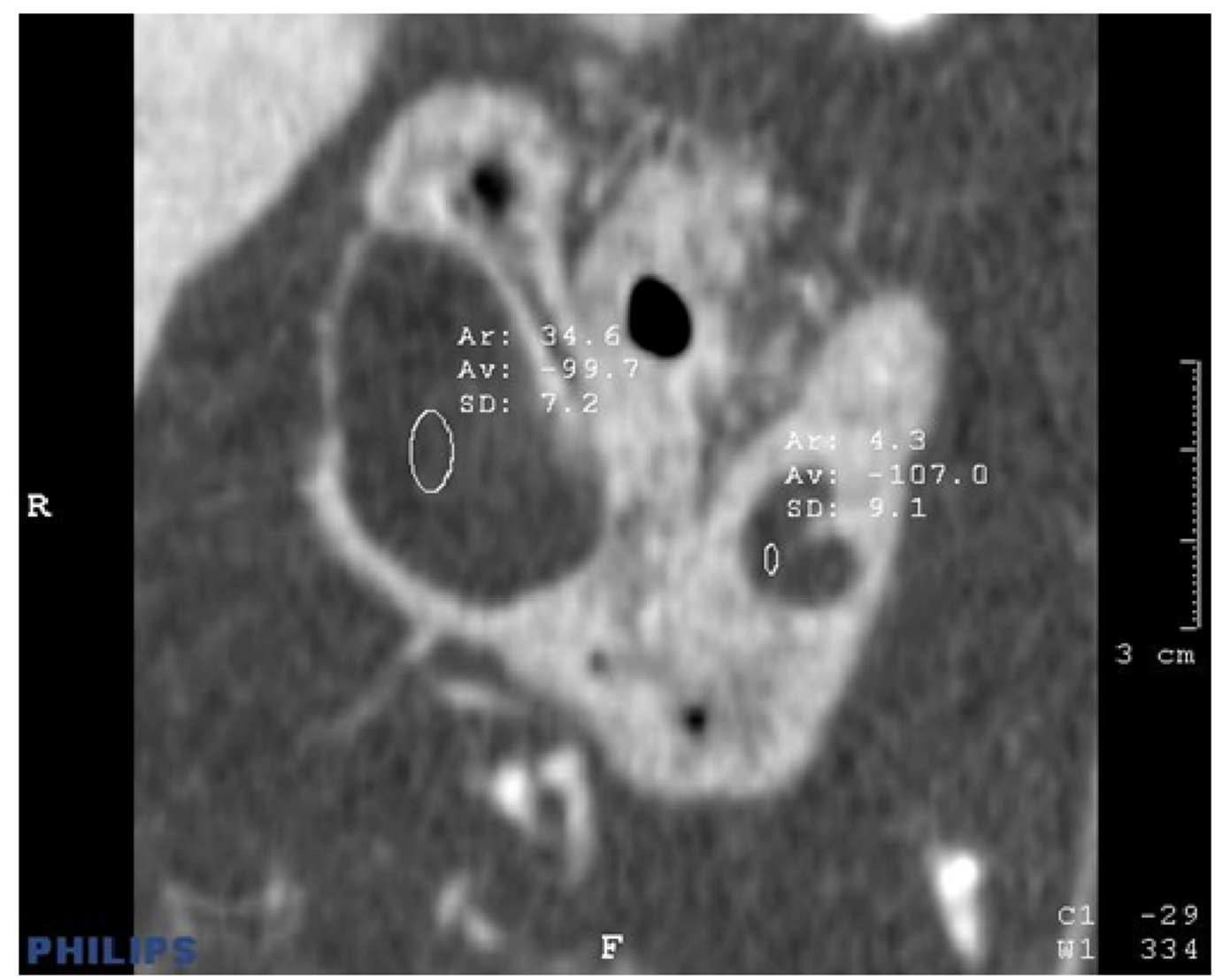

FIGURE 3: Coronal reformatted image of a computed tomography examination of the abdomen showing a bifocal lipoma of the small intestine

\section{Lipomas of the colon and rectum}

General Characteristics

The colon is the first location site of gastrointestinal lipomas. According to Agha and Thompson, lipomas of the colon represent $65 \%$ to $75 \%$ of all gastrointestinal lipomas [7, 30]. This percentage is $51.1 \%$ for Bruneton [4]. It is the second most common benign tumor of the distant colon after adenomas [8, 35], and it is estimated at $4 \%$ of all benign tumors of the colon [4]. The age of discovery is 50 to 70 years with a female predominance [44]. The cecum is the most frequent location site, followed by the right colon and the sigmoid [3, 30]. For Bruneton, lipomas of the colon and rectum are distributed as follows: $29.22 \%$ in the caecum, $20.9 \%$ in the right colon, $15.8 \%$ in the transverse colon, $29.7 \%$ at the left colon, and $4.4 \%$ in the rectum [4]. This distribution is quite the opposite of adenocarcinoma and colonic adenomatous polyps. Most of colonic lipomas are solitary but can be multifocal on the same colonic segment [30, 45] or on different segments [3]. The multifocal colonic lipomas are between $13 \%$ and $14 \%$ [1, 40]. The true lipoma of the ileocecal valve is to be differentiated from the frequent lipomatosis at this level. The true lipoma is a well-limited encapsulated greasy tumor, arising from the valve and would be then asymmetrical to this valve, contrary to lipomatosis which is a diffuse fatty infiltration and symmetrical to the valve [3, 30]. The average size of the colon lipoma is $3 \mathrm{~cm}$. Clinical latency concerns more than $30 \%$ of patients, and symptoms are not necessarily directly related to the lipoma [46]. As with all intestinal lipomas, a palpable mass corresponds generally to an intussusception, which is the main complication of colorectal lipomas. Exceptionally, 


\section{Cureus}

lipomas can be spontaneously externalized [9] or prolapsed through the rectum [47]. Colonoscopy can confirm the benign nature of the tumor when it is developing in submucosa or intraluminal [46]. This examination may be carried out before deciding on a possible endoscopic ablation [48]. In case of subserosal development or in case of giant form with clinical signs, surgery is performed rather than endoscopic ablation. If the lesion is asymptomatic, there is no treatment to propose.

\section{Imaging}

Radiological diagnosis based on the transparent appearance of lipomas is almost impossible to determine because of the interposition of intestinal gas.

Barium enema may show characteristic signs of sessile benign tumor (Figure 4) or pedunculated sometimes associated with signs of partial or complete intussusceptions [49-50]. Tumors less than $2 \mathrm{~cm}$ may not be seen on barium enema [44]. Colonic water enema recommended by some authors would be useful for the diagnosis since lipomas are less dense than water. However, this examination is requested because of the suspicion of lipoma, and its usefulness is limited by the fact that lipomas are not all radiolucent. This technique has lost favor over new radiological techniques. The conventional radiological aspect evokes rarely a malignant tumor. In 1985, Hall, et al. reported a caecal lipoma manifested by a gastrointestinal hemorrhage whose angiographic aspect suggested an angiodysplasia related to intratumoral vascular abnormalities; the hemorrhage was due to ulceration [51]. Ultrasound can show an echogenic mass, slightly hypoechoic, or with thin internal septations (Figure 5), but without vascular flow on Doppler examination (Figure 6). Computerized tomography has revolutionized the diagnosis of colorectal lipoma. It can affirm the diagnosis by showing a tumor greasy density between 80 to $-120 \mathrm{UH}$. CT is the first-line examination, enabling the definitive diagnosis of lipoma. Virtual colonoscopy appears to be very efficient for the diagnosis of the colonic lipoma. MRI should be more sensitive than CT for the detection of small lipomas [3, 5-6, 35, 52-53].

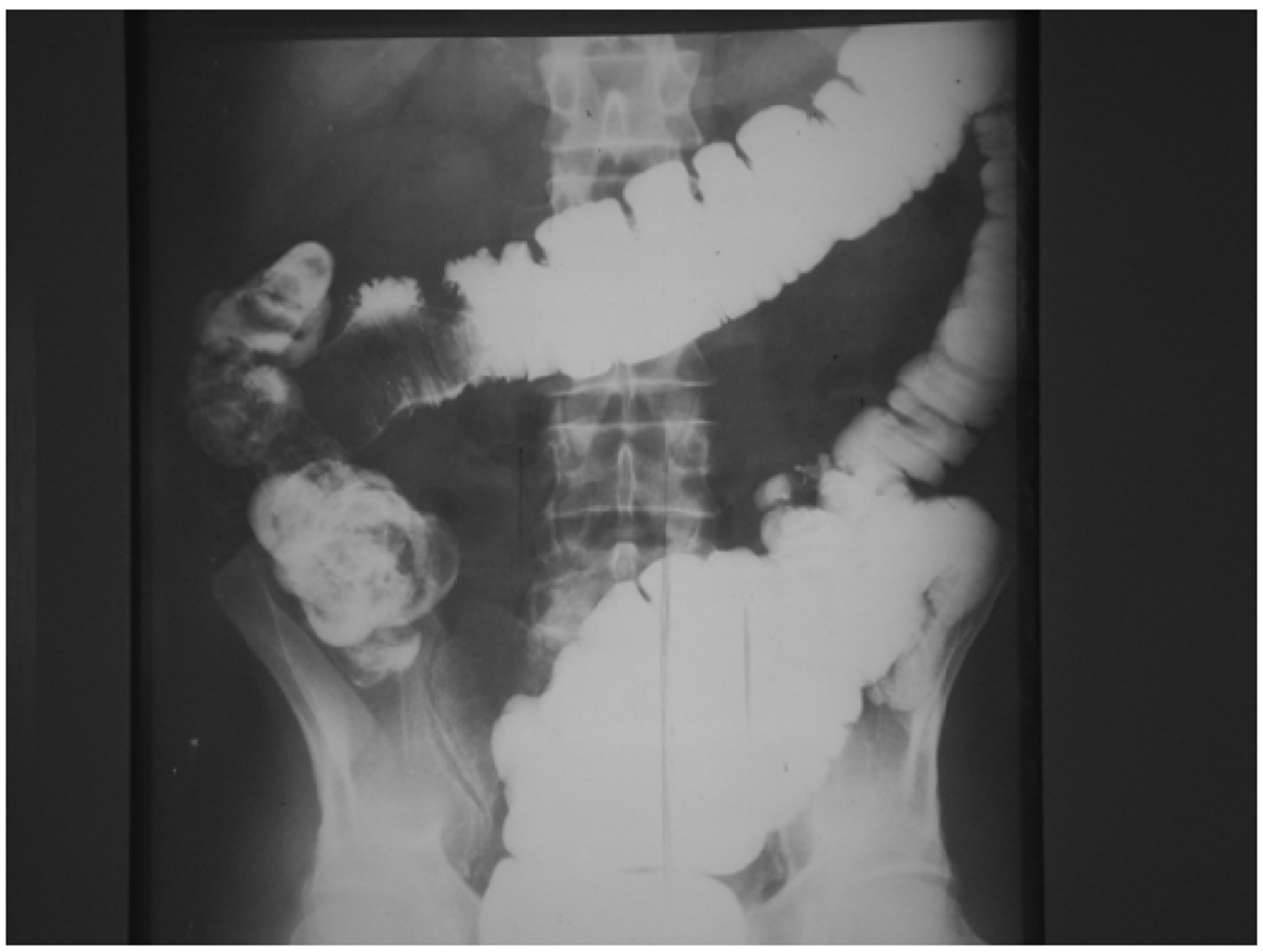




\section{Cureus}

FIGURE 4: Plain radiograph of the abdomen after barium enema showing an endoluminal lacuna with regular contours at the right angle of the colon evoking a benign tumor

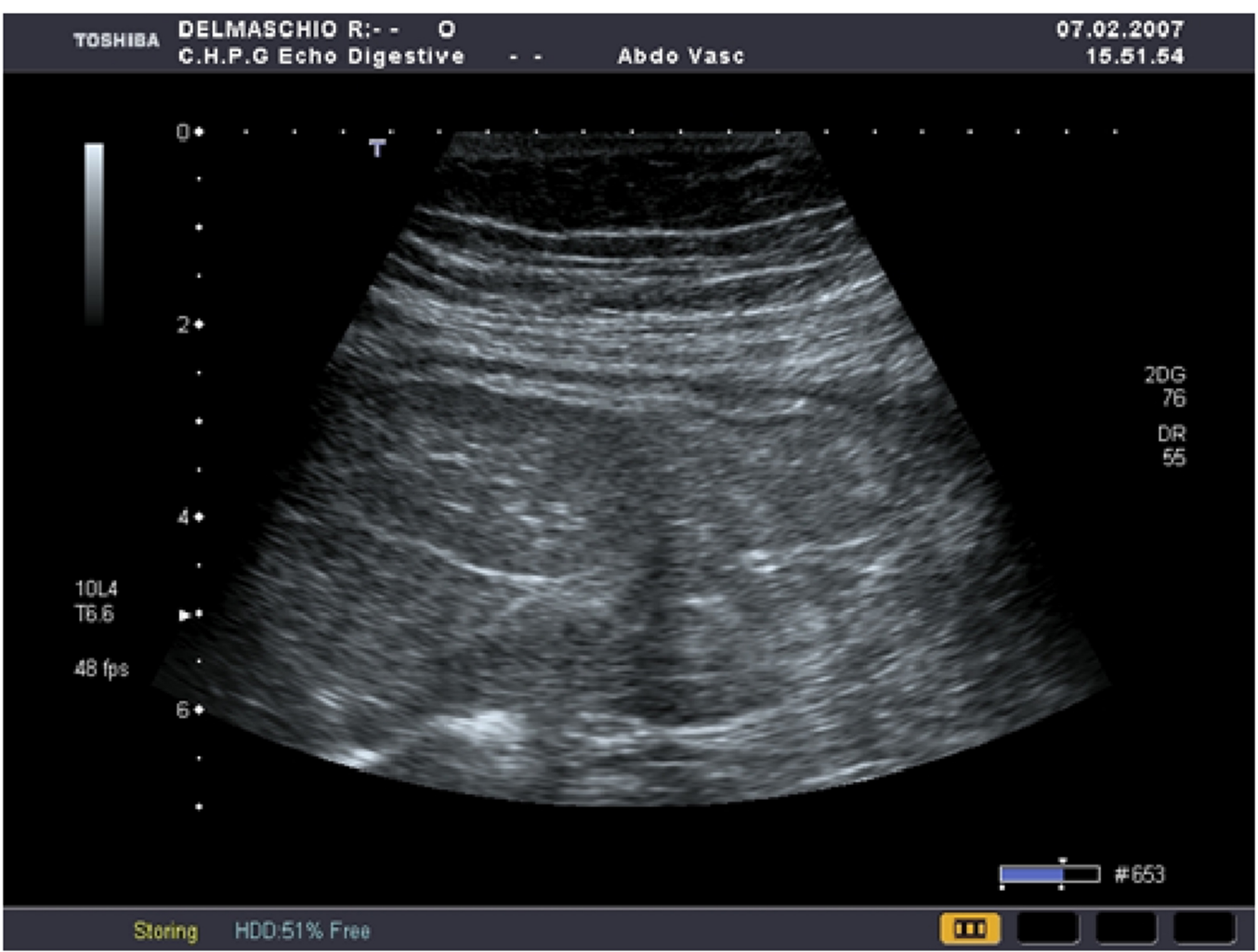

FIGURE 5: Sonographic axial image passing at the right hypochondrium region

Hypoechoic mass with internal thin septations in the right colon suspecting a lipoma. This is the same patient as Figure 4. 


\section{Cureus}

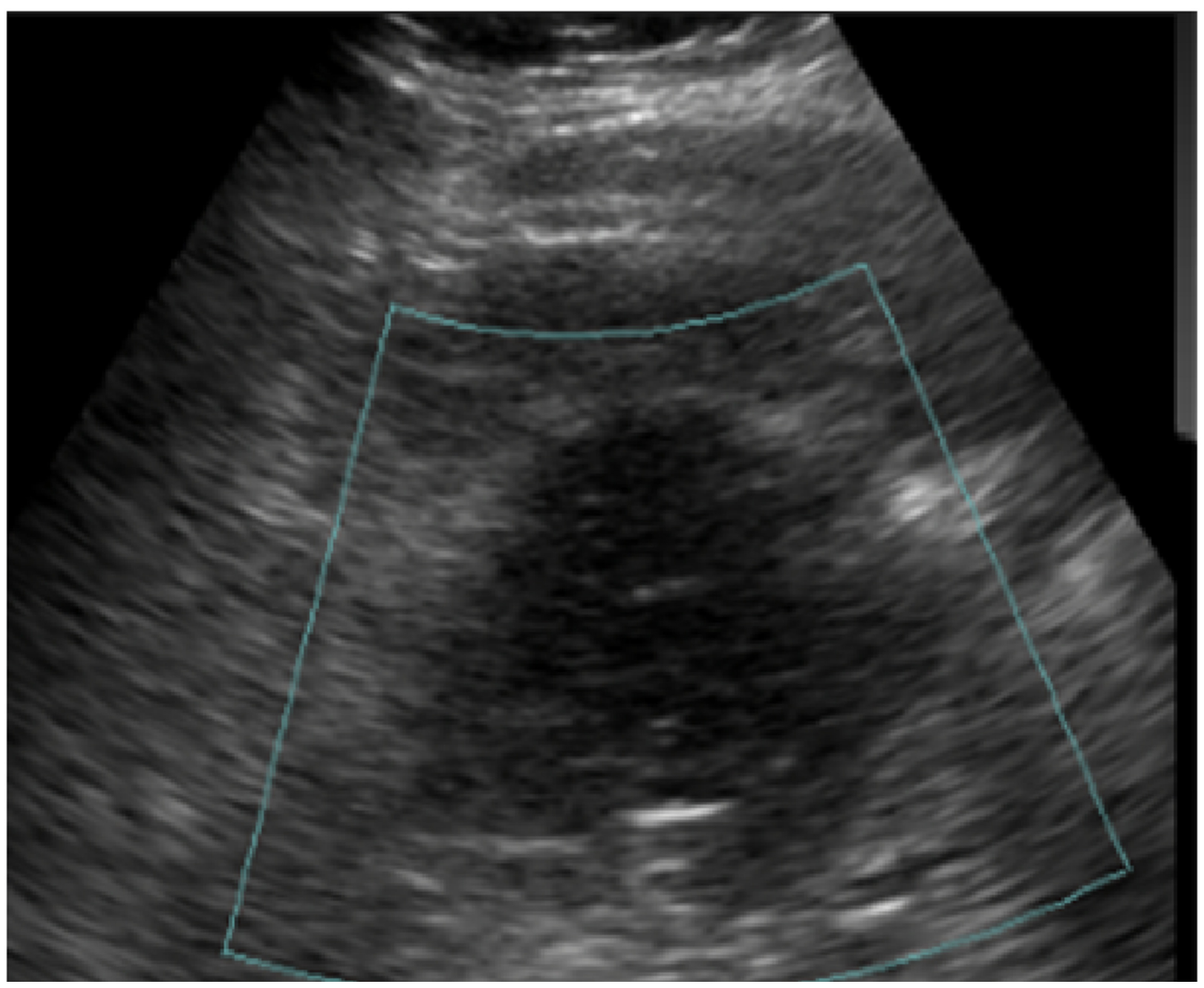

FIGURE 6: Sonographic axial image of a colonic lipoma demonstrating the absence of vascular flux at Doppler analysis

\section{Conclusions}

Lipomas of the gastrointestinal tract are non-epithelial benign tumors without risk of malignancy, but might rarely give rise to serious complications. The clinical manifestations vary according to the location and the size of these lesions. Conventional radiology, coupled with digestive opacification, allows suspecting the benign nature of the tumor. Ultrasound can rarely suspect the diagnosis. CT and MRI have revolutionized the diagnosis of this condition and allow follow-up in case of therapeutic abstention.

\section{Additional Information}

\section{Disclosures}

Conflicts of interest: In compliance with the ICMJE uniform disclosure form, all authors declare the following: Payment/services info: All authors have declared that no financial support was received from any organization for the submitted work. Financial relationships: All authors have declared that they have no financial relationships at present or within the previous three years with any organizations that might have an interest in the submitted work. Other relationships: All authors have declared that there are no other relationships or activities that could appear to have influenced the submitted work.

\section{References}

1. Weinberg T, Feldman M Sr: Lipomas of the gastrointestinal tract. Am J Clin Pathol. 1955, 
$25: 272-81$.

2. Katsinelos P, Chatzimavroudis G, Zavos C, Pilpilidis I, Lazaraki G, Papaziogas B, Paroutoglou G, Kountouras J, Paikos D: Cecal lipoma with pseudomalignant features: A case report and review of the literature. World J Gastroenterol. 2007, 13:2510-3.

3. Taylor AJ, Stewart ET, Dodds WJ: Gastrointestinal lipomas: A radiologic and pathologic review. AJR Am J Roentgenol. 1990, 155:1205-10.

4. Bruneton JN, Schmutz G: Lipoma. Imaging of Gastrointestinal Tract Tumors. Bruneton JN (ed): Springer Verlag, Berlin Heidelberg; 1990. 38-46.

5. Megibow AJ, Redmond PE, Bosniak MA, Horowitz L: Diagnosis of gastrointestinal lipomas by CT. AJR Am J Roentgenol. 1979, 133:743-5.

6. Nijssens M, Usewils R, Broeckx J, Ponette E, Baert AL: Lipoma of the duodenal bulb CT demonstration. Eur J Radiol. 1983, 3:39-41.

7. Agha FP, Dent TL, Fiddian-Green RG, Braunstein AH, Nostrant TT: Bleeding lipomas of the upper gastrointestinal tract. A diagnostic challenge. Am Surg. 1985, 51:279-85.

8. Fernandez MJ, Davis RP, Nora PF: Gastrointestinal lipomas. Arch Surg. 1983, 118:1081-3.

9. Deeths TM, Madden PN, Dodds WJ: Multiple lipomas of the stomach and duodenum . Am J Dig Dis. 1975, 20:771-4.

10. Fawcett NW, Bolton VL, Geever EF: Multiple lipomas of the stomach and duodenum . Ann Surg. 1949, 129:524-7.

11. Suárez Moreno RM, Hernández Ramírez DA, Madrazo Navarro M, Salazar Lozano CR, Martínez Gen R: Multiple intestinal lipomatosis. Case report (article in English, Spanish) . Cir Cir. 2010, 78:163-5.

12. Wan XY, Deng T, Luo HS: Partial intestinal obstruction secondary to multiple lipomas within jejunal duplication cyst: A case report. World J Gastroenterol. 2010, 16:2190-2.

13. Liu X, Wilcox CM, Nodit L, Lazenby AJ: Multiple gastrointestinal stromal tumors and lipomatosis. Arch Pathol Lab Med. 2008, 132:1825-9. 10.1043/1543-2165-132.11.1825

14. Franc-Law JM, Bégin LR, Vasilevsky CA, Gordon PH: The dramatic presentation of colonic lipomata: Report of two cases and review of the literature. Am Surg. 2001, 67:491-4.

15. Grosdidier J, Boissel P, Baudession D, Baudesson D, Lefakis P: Gastric lipomas (article in French). J Chir (Paris). 1974, 108:47-56.

16. Theunis A, Dony A, Dewitte C, Serste JP, Deschreyer M: Hemorrhage from the upper digestive tract originating in a large lipoma of the gastric body (article in French). Acta Gastroenterol Belg. 1979, 42:294-8.

17. Della Volpe N, Bianco L, Bonuso C, Annecchiarico M, Di Silverio P, Caiazza A: Rare ileal localisation of angiolipoma presenting as chronic haemorrhage and severe anaemia: A case report. J Med Case Rep. 2008, 2:129. 10.1186/1752-1947-2-129

18. Troisier J, Bariety M, Brouet G: Submucosal lipomas of the stomach (article in French) . Arch Mal Appar Dig. 1936, 26:87-97.

19. Lefort C: Gastric submucosal tumors. Classification, diagnosis and investigations, treatment (article in French). FMC Hepato-Gastro-Entérol. 2007, 183-192.

20. Bak YT, Kim JH, Kim JG, Lee CH, Lee KN, Choi YH, Kim HJ: Liposarcoma arising in a giant lipomatous polyp of the esophagus. Korean J Intern Med. 1989, 4:86-9.

21. Hirsch F, Ernalsteen J, Wilputte M: Retroperitoneal lipoma. Sarcomatous transformation. Acta Gastroenterol Belg. 1965, 28:207-17.

22. Ongari M, Bazzoni C, Serini M, Alleva M, Sguazzini C, Lombardi C: Sarcomatous degeneration of a giant scrotal lipoma. Presentation of a clinical case (article in Italian). Minerva Urol Nefrol. 1993, 45:73-5.

23. Thomas J: Retroperitoneal xanthomatous fibrolipoma with sarcomatous degeneration obstructing labor (Article in undetermined language). Zentralbl Gynakol. 1952, 74:1228-37.

24. Milgram JW: Malignant transformation in bone lipomas. Skeletal Radiol. 1990, 19:347-52.

25. Sockeel P, Massoure MP: Colonic lipoma and familial multiple lipomatosis: a chance association? (article in French). Gastroenterol Clin Biol. 2008, 32:872-3.

10.1016/j.gcb.2008.03.015

26. Keskin D, Ezirmik N, Celik H: Familial multiple lipomatosis. Isr Med Assoc J. 2002, 4:1121-3.

27. Hasan N, Mandhan P: Respiratory obstruction caused by lipoma of the esophagus . J Pediatr Surg. 1994, 29:1565-6.

28. Samad L, Ali M, Ramzi H, Akbani Y: Respiratory distress in a child caused by lipoma of the esophagus. J Pediatr Surg. 1999, 34:1537-8. 
29. Fumagalli U, Bona S, Battafarano F, Bonifacio C, Narne S, Peracchia A, Rosati R: Transoral surgical removal of a giant fibrolipoma of the esophagus: case report. Gastroenterol Clin Biol. 2008, 32:866-9. 10.1016/j.gcb.2008.06.001

30. Thompson WM: Imaging and findings of lipomas of the gastrointestinal tract. AJR Am J Roentgenol. 2005, 184:1163-71.

31. Allen MS Jr, Talbot WH: Sudden death due to regurgitation of a pedunculated esophageal lipoma. J Thorac Cardiovasc Surg. 1967, 54:756-8.

32. Salo JA, Kiviluoto T, Heikkilä L, Perhoniemi V, Lamminen A, Kivilaakso E: Enucleation of an intramural lipoma of the oesophagus by videothoracoscopy. Ann Chir Gynaecol. 1993, 82:669.

33. Liliequist B, Wiberg A: Pedunculated tumours of the oesophagus. Two cases of lipoma . Acta Radiol Diagn (Stockh). 1974, 15:383-92.

34. Lassen K, Revhaug A, Gauperaa T, Kearney M: Pedunculated lipoma of the oesophagus in a patient with achalasia. Eur J Surg. 2002, 168:741-3.

35. Heiken JP, Forde KA, Gold RP: Computed tomography as a definitive method for diagnosing gastrointestinal lipomas. Radiology. 1982, 142:409-14.

36. Chu AG, Clifton JA: Gastric lipoma presenting as peptic ulcer: Case report and review of the literature. Am J Gastroenterol. 1983, 78:615-8.

37. Thompson WM, Kende AI, Levy AD: Imaging characteristics of gastric lipomas in 16 adult and pediatric patients. AJR Am J Roentgenol. 2003, 181:981-5.

38. Crowe MJ, Harte P, Dawson K, Power RF: Gastric lipoma as a cause of upper gastrointestinal bleeding. Ir Med J. 1986, 79:13-4.

39. Pérez Cabañas I, Rodríguez Garrido J, De Miguel Velasco M, Ortiz Hurtado H: Gastric lipoma: an infrequent cause of upper digestive hemorrhage (article in Spanish). Rev Esp Enferm Dig. 1990, 78:163-5.

40. Bruneton JN, Quoy AM, Dageville X, Lecomte P: Lipomas of the digestive tract. Review of the literature apropos of 5 cases (article in French). Ann Gastroenterol Hepatol (Paris). 1984, 20:27-32.

41. Hajzman M, Síma P, Karnos V, Haas M: Submucous lipoma as a cause of invagination in adulthood (article in Czech). Rozhl Chir. 2010, 89:459-60.

42. Long BW, Goodwin E, Halford P, Almas J: Diagnosis and endoscopic resection of a bleeding duodenal lipoma. J Miss State Med Assoc. 2008, 49:3-6.

43. Jansen JB, Temmerman A, Tjhie-Wensing JW: Endoscopic removal of large colonic lipomas (article in Dutch). Ned Tijdschr Geneeskd. 2010, 154:A2215.

44. Castro EB, Stearns MW: Lipoma of the large intestine: A review of 45 cases . Dis Colon Rectum. 1972, 15:441-4.

45. Wychulis AR, Jacherman RJ, Mayo CW: Submucous lipomas of the colon and rectum . Surg Gynecol Obstet. 1964, 118:337-40.

46. Paškauskas S, Latkauskas T, Valeikaitė G, Paršeliūnas A, Svagždys S, Saladžinskas Z, Tamelis A, Pavalkis D: Colonic intussusception caused by colonic lipoma: A case report . Medicina (Kaunas). 2010, 46:477-81.

47. De Beer RA, Shinya H: Colonic lipomas. An endoscopic analysis. Gastrointest Endosc. 1975, 22:90-1.

48. Messer J, Waye JD: The diagnosis of colonic lipomas--the naked fat sign. Gastrointest Endosc. 1982, 28:186-8.

49. Margulis AR, Jovanovich A: The roentgen diagnosis of submucous lipomas of the colon . Am J Roentgenol Radium Ther Nucl Med. 1960, 84:1114-20.

50. Michowitz M, Lazebnik N, Noy S, Lazebnik R: Lipoma of the colon. A report of 22 cases . Am Surg. 1985, 51:449-54.

51. Hall PA, Murfitt J, Pollock DJ: Caecal lipomas mimicking colonic angiodysplasia . Br J Radiol. 1985, 58:1213-4.

52. Chiba T, Suzuki S, Sato M, Tsukahara M, Saito S, Inomata M, Orii S, Suzuki K: A case of a lipoma in the colon complicated by intussusception. Eur J Gastroenterol Hepatol. 2002, 14:701-2.

53. Shin NY, Kim MJ, Chung JJ, Chung YE, Choi JY, Park YN: The differential imaging features of fat-containing tumors in the peritoneal cavity and retroperitoneum: the radiologicpathologic correlation. Korean J Radiol. 2010, 11:333-45. 10.3348/kjr.2010.11.3.333 